\section{(6) OPEN ACCESS}

\title{
Geographical and temporal variation of injection drug users in Pakistan
}

\author{
Chris P Archibald, ${ }^{1}$ Souradet $Y$ Shaw, ${ }^{2}$ Faran Emmanuel, ${ }^{3}$ Suleman Otho, ${ }^{3}$ \\ Tahira Reza, ${ }^{3}$ Arshad Altaf, ${ }^{3}$ Nighat Musa, ${ }^{3}$ Laura H Thompson, ${ }^{2}$ James F Blanchard ${ }^{2}$
}

${ }^{1}$ Centre for Communicable Diseases and Infection Control, Public Health Agency of Canada, Ottawa, Ontario, Canada

${ }^{2}$ Centre for Global Public Health, University of Manitoba, Winnipeg, Manitoba, Canada ${ }^{3}$ HIVIAIDS Surveillance Project, Islamabad, Pakistan

\section{Correspondence to}

Dr James F Blanchard, Centre for Global Public Health, Department of Community Health Sciences, University of Manitoba, R070-771 McDermot Avenue, Winnipeg, MB R3E 0T6;

james_blanchard@umanitoba.ca

Received 25 July 2012 Revised 19 November 2012 Accepted 9 December 2012 Published Online First 11 January 2013

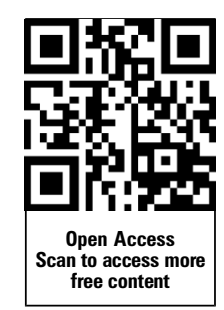

To cite: Archibald $C P$, Shaw SY, Emmanuel F, et al. Sex Transm Infect 2013;89: ii18-ii28.

\section{ABSTRACT}

Objectives We describe the characteristics of injecting drug users (IDU) in Pakistan in 2006 and 2011, and assess the heterogeneity of IDU characteristics across different cities and years as well as factors associated with HIV infection.

Methods Cross-sectional, integrated behaviouralbiological surveys of IDU were conducted in 10 cities across Pakistan in 2006 and 2011. Univariate and multivariable analyses were used to describe the differences in HIV prevalence and risk behaviours between cities and over time.

Results Large increases in HIV prevalence among injection drug users in Pakistan were observed, with overall HIV prevalence increasing from $16.2 \%$ in 2006 to $31.0 \%$ in 2011; an increase in HIV prevalence was also seen in all geographic areas except one. There was an increase in risk behaviours between 2006 and 2011, anecdotally related to a reduction in the availability of services for IDU. In 2011, larger proportions of IDU reported injecting several times a day and using professional injectors, and fewer reported always using clean syringes. An increase in the proportion living on the street was also observed and this was associated with HIV infection. Cities differ in terms of HIV prevalence, risk profiles, and healthcare seeking behaviours.

Conclusions There is a high prevalence of HIV among injection drug users in Pakistan and considerable potential for further transmission through risk

behaviours. HIV prevention programs may be improved through geographic targeting of services within a city and for involving groups that interact with IDU (such as pharmacy staff and professional injectors) in harm reduction initiatives.

\section{INTRODUCTION}

Injecting drug use has long played a prominent role in determining the unfolding of the HIV epidemic in various countries around the world. ${ }^{1-7}$ Drug use is very complex in Pakistan which is in close geographical proximity to some of the world's major drug production areas and is itself a large opiate producing area with a long history of drug use, ${ }^{8}$ with approximately 5 million drug users by some estimations. 9 Pakistan is also one of the principal trafficking routes for opiates smuggled from Afghanistan, the world's largest producer of opium. These factors have had significant influence on local drug consuming markets, resulting in substantial numbers of drug users, ${ }^{10}$ including a significant number who have transitioned to injecting drug use $^{11} 12$ which is now well established in nearly all larger cities throughout the country. The
2006-2007 National AIDS Control Program report estimated over 31000 injecting drug users (IDUs) across the 12 cities it surveyed. ${ }^{13}$ This same report showed that IDUs in Pakistan tended to be older men (median age 32 years), unmarried (>50\%) and illiterate $(>55 \%)$, with the average injection duration being about 5 years. ${ }^{13}$ HIV prevalence was reported to be $15.8 \% \quad(95 \%$ CI $14.7 \%$ to $16.9 \%)$, with the highest rates in Sargodha (51.3\%, $95 \%$ CI $46.4 \%$ to $56.1 \%$ ) and the lowest in Bannu $(1.4 \%$; $95 \%$ CI $0.3 \%$ to $7.4 \%){ }^{13}$

Early data indicated high rates of needle sharing in some cities ${ }^{14}$ and high prevalence rates of hepatitis C, but low prevalence of HIV infection. ${ }^{15}$ However, in 2004, the first significant outbreak of HIV occurred in Pakistan in Larkana among IDUs. $^{16}$ Since then, HIV has spread among Pakistan's IDU population, but there is significant variability across the country. The reason for this heterogeneity has not been established and there is a need to better understand the heterogeneity of this population and risk behaviours to guide HIV prevention and control interventions for IDUs across Pakistan. For example, the city of Quetta, which lies adjacent to the Afghanistan border, is thought to have the highest rates of injection drug use, with concomitantly higher rates of HIV among its IDUs; one study reported an HIV prevalence of $24 \% .^{9}$ In addition, types of drugs injected vary widely. One report found the highest rates of heroin use in Larkana, Sargodha, Karachi and Quetta cities (>75\%). In contrast, IDUs from cities like Gujurat, Lahore and Sukkur predominantly used diazepam. ${ }^{13}$ This paper describes the results of a series of cross-sectional behavioural and biological surveys among IDUs in Pakistan between 2006 and 2011. It also assesses the heterogeneity of IDU characteristics across different cities and time, and factors associated with prevalent HIV infection in the latter period.

\section{METHODS}

\section{Data collection/recruitment methods}

Data on IDUs were collected from a series of crosssectional behavioural and biological surveys of key subpopulations of HIV risk (including IDUs, male sex workers (MSWs) and female sex workers (FSWs)). These surveys were conducted under a national strategy of second-generation HIV surveillance, the objective of which was to provide trend data in biological and behavioural information related to HIV. Four rounds of data on IDUs were available, collected in 2005 (round 1), 2006 (round 2), 2008 (round 3) and 2011 (round 4); cities representing all four provinces of Pakistan 
(Sindh, Punjab, Khyber-Pakhtunkhwa and Balochistan) were included (figure 1). For the purposes of this study, and to be consistent with other studies in this supplement, only data from rounds 2 (2006) and 4 (2011) are presented as these rounds surveyed the largest number of cities. In these two rounds, only cities that were surveyed at both points in time were retained for analyses. Thus, from Punjab province, Lahore (the capital city), Dera Ghazi Khan, Faisalabad, Multan and Rawalpindi were included; from Sindh province, Karachi (the capital city), Larkana and Sukkur were included; for Balochistan and Khyber provinces, Quetta and Peshawar were included, respectively. For Punjab and Sindh provinces, the non-capital cities were aggregated to simplify analyses. Therefore, data for IDUs are presented in the geographical categories of Lahore, Other Punjab, Karachi, Other Sindh, Quetta and Peshawar.

In each round, IDUs were recruited and interviewed individually by trained peer workers using the same sampling methodology which has been described previously. ${ }^{17-19}$ Briefly, multistage cluster sampling techniques (informed by previous mapping exercises used to estimate the size of IDU populations) were used to create a representative sample of IDUs in each city. In the first stage, sampling weights were calculated based on the number of IDUs in each geographical zone, and the total number of IDUs to be sampled was proportionately allocated to all zones. In the next stage, the top 10 IDU gathering places (spots) in each zone were identified from the mapping data, and

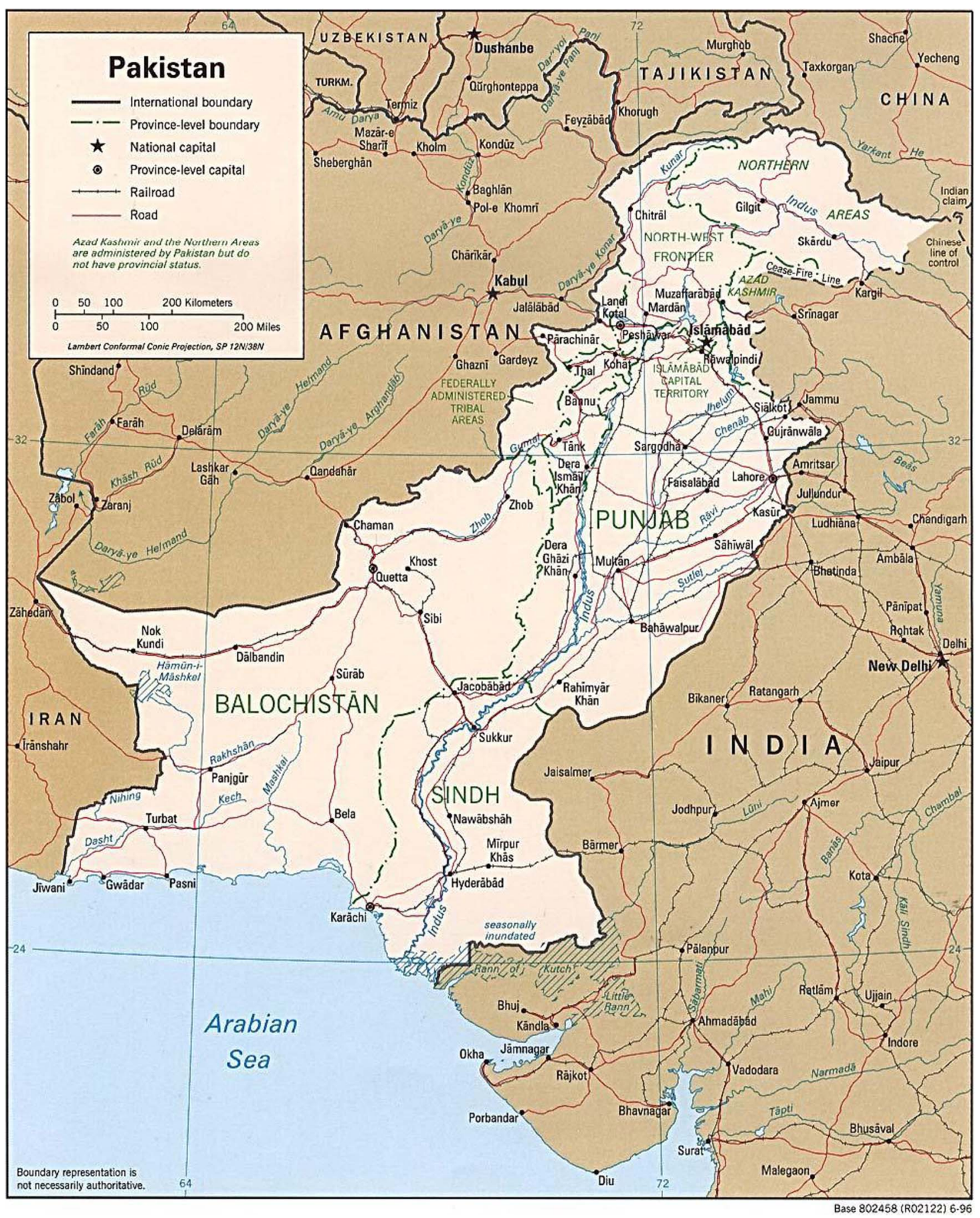

Figure 1 Base map (retrieved from http://mappery.com/map-of/Pakistan-Map-2 on 10 October 2012). 
the study participants were recruited by team members with the help of social mobilisers hired specifically for this purpose. The social mobilisers identified all eligible participants at a selected spot, and the recruiter then randomly selected people to be approached and asked for consent to participate in the study. If the eligible participant refused, the next available community member was approached for recruitment (the refusal rate was less than $1 \%$ in each round). A sample size of 400 was targeted in each city, as previous work in South Asia (including in Pakistan) has demonstrated that this sample size gave sufficient power to meet the following criteria: measure prevalence of a characteristic that is present in $50 \%$ of the population with a precision of $\pm 5 \%$; detect a $25 \%$ difference in a characteristic that has a prevalence of $40 \%$; measure HIV prevalence with a precision of $\pm 2 \%$ if the prevalence is approximately $5 \%$; and detect $(\mathrm{p}<0.05)$ a doubling in HIV prevalence if the baseline prevalence is between $5 \%$ and $6 \%$. When mapping data estimated an IDU population size of less than 400, all eligible people found in the city were asked to participate.

IDUs were defined as 'any person who has injected drugs for non-therapeutic purposes in the past 6 months'. Exclusion criteria included the following: age under 18 years of age; unwillingness to participate or to provide informed consent; incapable of understanding the information provided about the survey (eg, due to intoxication or cognitive barriers, etc); and previous participation in the survey in the present round of data collection. Following a process to obtain informed consent for biological and behavioural components, trained field workers administered a structured questionnaire to study participants. Questionnaires were designed in English, but were translated and administered in Urdu; IDUs were interviewed in a central field office. Biological data were gathered using the capillary 'dried blood spot' (DBS) methodology; DBS specimens were screened using ELISA/enzyme immunoassay (Bio-Rad USA, Berkeley, CA, USA) and samples that tested positive were subsequently confirmed in duplicate by the Vironostika HIV Uni-Form II EIA (bioMériux, The Netherlands). The Genetic Systems HIV-1 Western Blot (Bio-Rad USA) was used to confirm the status of any specimen found to be indeterminate after EIA testing.

After questionnaires were completed, individuals were debriefed and given the chance to ask any follow-up questions. At this debriefing session, individuals were provided with information on the modes of transmission and prevention of HIV infection, and were made aware of existing services; HIV results from this study were not returned to participants and all participants were referred to free local voluntary HIV counselling and testing centres. The institutional review boards of the Public Health Agency of Canada and the University of Manitoba approved the study.

\section{Measures}

Questionnaires collected information on socio-demographic characteristics, drug use and sexual behaviours, and healthcare seeking behaviour; however, the question on whether IDUs were aware of any Government of Pakistan services for IDUs was the only question on healthcare-seeking behaviour that was consistent across rounds 2 and 4. Age (categorised as $<20$, 20-24, 25-29, 30-34, 35-39, 40+ years), education level (illiterate, primary school only, middle school or more), marital status (unmarried, currently married, separated/divorced/ widowed), where respondents resided (home, hostel/hotel, street/lane/other), and with whom they lived (alone, relatives/ family, friends/other) were used as socio-demographic variables.
Variables used to describe drug injecting behaviours were types of drugs injected among the overall top four drugs used (avil, diazepam, tamgesic, heroin), duration of drug injecting habit (1 year or less, 2-4 years, 5-9 years, 10+ years), frequency of daily injection, both in the past month (once a day, two to three times a day, more than four times a day) and at last injection (none, one to two times a day, more than three times a day), whether a clean syringe was always used for injections in the past month, use of a professional injector (in the past month and at last injection), venue of last injection (dichotomised into public vs non-public places), person with whom last injection occurred (dichotomised into 'no one' and 'somebody else'), use of a dirty syringe at last injection, and whether a syringe or other injection equipment was passed to someone else at last injection. A professional injector is an individual, likely a drug provider who will inject IDUs for a fee, often using a previously used syringe. Sexual behaviour characteristics were measured as age at first sex $(10-14,15-19,20+)$, whether respondents had had paid sex with a FSW in the past 6 months, whether a condom was used at last paid sex act with a FSW, whether respondents paid for sex with a MSW or hijra (transgender) sex worker (HSW) in the past 6 months, whether a condom was used at last MSW/HSW sex, and whether respondents ever practiced exchange sex.

\section{Statistical analyses}

Socio-demographic, drug-injecting and sexual behaviour characteristics were compared across rounds 2 and 4 by geographical area. To test for statistically significant differences between rounds, $\chi^{2}$ tests of association were used, comparing rounds 2 and 4 . To reduce the number of comparisons, and because the study was powered to detect changes in HIV prevalence and proportion of injectors who used an unclean syringe, we focused on these two outcomes only. As we were ostensibly testing seven geographical areas (Lahore, Other Punjab, Karachi, Other Sindh, Quetta, Peshawar and All Cities), we used the Bonferonni correction to reduce the possibility of a type I error. Thus, for each outcome, $\mathrm{p}<0.007(0.05 / 7)$ was used as the threshold for statistical significance. Multivariable logistic regression analysis was applied to round 4 data for each of the two largest provinces (Punjab and Sindh) to assess factors associated with HIV status, use of dirty syringe at last injection, and use of a professional injector at last injection. Adjusted ORs (AORs) and 95\% CIs were estimated for models examining dependent variables that were significant at the $\mathrm{p}<0.1$ level, with cities aggregated within provinces. Due to their importance in previous research, for each model, age, education level, injection length, frequency of injection (yesterday), where last injected, who last injected with, use of a dirty syringe, types of drug injected, sex with FSW (in the past 6 months), sex with a MSW/ HSW (in the past 6 months), and whether the respondent ever engaged in paid sex were all a priori selected for inclusion into final multivariable models. For comparison with models investigating HIV status as the outcome, variables included in the final HIV model were also used in the final models for use of dirty syringe and use of a professional injector at last injection. As there were three outcomes tested and for each province, variables were considered statistically significant at the $\mathrm{p}<0.017$ level. Stata 11 was used for all analyses.

\section{RESULTS}

Table 1 displays socio-demographic, drug-injecting, and sexual behaviour characteristics for round 2 (2006) and round 4 (2011) by geographical area. In addition, awareness of 
government IDU services and HIV prevalence are also shown. Overall, HIV prevalence among IDUs in Pakistan increased from $16.2 \%$ in 2006 to $31 \%$ in 2011 . With the exception of Quetta, all geographical areas reported an increase in HIV prevalence, with the most dramatic being an increase in HIV prevalence from $6.5 \%$ to $30.7 \%$ in Lahore. Karachi reported the highest HIV prevalence in both rounds, at $30 \%$ and $43 \%$, respectively. In terms of socio-demographic characteristics, the mean age across all cities dropped from 32.4 years to 31 years from 2006 to 2011. The proportion of IDUs who were illiterate decreased from $58.7 \%$ to $52.6 \%$, while the proportion of those reporting living on the streets increased from $20.6 \%$ to $35.3 \%$.

\section{Drug-injecting behaviours: last month}

The proportion of IDUs who reported an injecting duration of 1 year or less increased from $13.5 \%$ to $16.1 \%$ from 2006 to 2011. For specific geographical areas, this proportion increased from $9.8 \%$ to $15.3 \%$ in Lahore, from $12.8 \%$ to $21 \%$ in Other Punjab, from $7.6 \%$ to $18.4 \%$ in Karachi and from $14.4 \%$ to $16.8 \%$ in Quetta. Notably, over 50\% of IDUs from Peshawar reported injecting drugs for a year or less in 2006 (compared with $13.5 \%$ for all cites); this proportion decreased to $25.1 \%$ in 2011.

The proportion of IDUs who reported injecting four times or more per day in the last month increased from $19.8 \%$ to $23.3 \%$ overall, with increases observed in all geographical areas except Peshawar. The proportion of IDUs reporting always using a clean syringe in the last month decreased from $43.3 \%$ to $23.5 \%$ overall, while the proportion of those reporting use of a professional injector at least once during the last month increased from $25.2 \%$ to $68.1 \%$. Of note, in 2011 , only $4.8 \%$ of IDUs from Quetta reported always using a clean syringe in the last month (down from $55.6 \%$ in 2006), while use of professional injectors in the last month was highest among IDUs from cities in the Other Punjab category, at 78.3\%.

\section{Drug-injecting behaviours: last injection}

Frequency of injecting three or more times the previous day increased from $39.2 \%$ to $62.3 \%$, with increases observed in all geographical areas except Peshawar where it slightly decreased from $30.5 \%$ to $27.7 \%$. Injecting in public places at last injection increased from $68.3 \%$ in 2006 to $86.1 \%$ in 2011 . The proportion of IDUs reporting use of a dirty syringe at last injection increased from $28.4 \%$ to $37.9 \%$, with IDUs in cities from the Other Punjab category reporting the highest prevalence of this behaviour, at 45.3\%. Between 2006 and 2011, use of a professional injector at last injection increased from $10.9 \%$ to $35.9 \%$. Types of drug injected showed substantial changes between rounds. For example, the use of heroin among all cities increased from $44.6 \%$ to $72.6 \%$, while the use of tamgesic decreased from $27 \%$ to $12.5 \%$. In $2011,96.9 \%$ of IDUs from Karachi reported using heroin, an increase from $76.2 \%$ in 2006. It should be noted that many of the drugs used by IDUs in Pakistan (including avil and diazepam) are easily available over the counter from nearly all pharmacies in the country and there is no age limit for buying these drugs.

\section{Sexual behaviours}

The proportion of IDUs reporting paying for sex with a FSW in the last 6 months decreased slightly, from $22.4 \%$ in 2006 to $20.7 \%$ in 2011. Decreases in this behaviour were observed among IDUs from Lahore, Other Punjab and Karachi, while this behaviour increased in Other Sindh, Quetta and Peshawar. Among those reporting paying for sex with a FSW, condom use increased from $14.7 \%$ to $23.2 \%$ between the two rounds, with substantial heterogeneity by geographical area. The proportion of IDUs reporting paying for sex with a MSW/HSW in the last 6 months decreased from $12.8 \%$ to $9.2 \%$. At the same time, among IDUs who reported paying for sex with a MSW/HSW, condom use increased from $12 \%$ to $19.2 \%$ between the two rounds. The proportion of IDUs reporting ever being involved with sex work declined slightly, from $16.5 \%$ in 2006 to $14.2 \%$ in 2011. Finally, the proportion of IDUs reporting being aware of services for IDUs provided by the Government of Pakistan decreased slightly from $32.4 \%$ to $29.2 \%$; the pattern of less awareness of government services in 2011 was actually quite pronounced in all areas except Karachi and Quetta where awareness increased.

\section{Multivariable analyses \\ HIV infection}

Table 2 shows AORs and their 95\% CIs from a multivariable model examining the correlates of HIV infection from round 4 (2011) data for Punjab province. After adjustment for all variables included in the model, HIV infection was significantly associated with having little or no formal education, place of residence, a longer duration of injecting drug use, and not injecting avil or diazepam. For example, longer duration of injection drug use was associated with an increased likelihood of HIV infection: compared with those reporting injecting for 1 year or less, IDUs who reported injecting for 2-4 years and $5-9$ years were $1.49(95 \% \mathrm{CI} 1.1$ to $2.0 ; \mathrm{p}=.006)$ and 1.61 (95\% CI 1.1 to $2.3 ; \mathrm{p}=0.007$ ) times more likely to have HIV infection, respectively. Compared with IDUs who were illiterate, those reporting having primary school education only were 0.68 (95\% CI 0.5 to $0.9 ; \mathrm{p}=0.004$ ) times less likely to have HIV infection. IDUs who injected avil (AOR $0.6,95 \%$ CI 0.4 to 0.8 ; $\mathrm{p}=0.002$ ) or diazepam (AOR $0.6,95 \%$ CI 0.5 to $0.8 ; \mathrm{p}=0.002$ ) were also less likely to have HIV infection.

In comparison, factors associated with HIV infection among IDUs from Sindh province (table 3 ) included younger age, being separated or divorced, living on the street, being involved in sex work and awareness of IDU programmes. Compared with those younger than 20 years of age, IDUs who were aged 35-39 years and 40 years or more were $0.27(95 \%$ CI 0.1 to $0.7 ; \mathrm{p}=0.004)$ and $0.21(95 \%$ CI 0.1 to $0.5 ; \mathrm{p}=0.001)$ times less likely to have HIV infection, respectively. Of some note, IDUs who reported sex work were more likely (AOR 2.25, 95\% CI 1.2 to 4.3; $\mathrm{p}=0.013$ ) to have HIV infection, as were those who reported being aware of IDU services (AOR 1.59, 95\% CI 1.1 to 2.2; $\mathrm{p}=0.009$ ). Finally, in contrast to IDUs from Punjab province, IDUs reporting living on the streets were more likely to have HIV infection (AOR $1.45,95 \%$ CI 1.0 to $2.1 ; \mathrm{p}=0.039$ ).

Use of a dirty syringe and use of a professional injector at last injection

Tables 2 and 3 also show the results of multivariable models examining the correlates of using a dirty syringe at last injection among IDUs from Punjab and Sindh provinces, respectively. Variables positively associated with using a dirty syringe at last injection for IDUs from Punjab include living in a hostel/hotel (AOR $1.63,95 \%$ CI 1.2 to $2.2 ; \mathrm{p}=0.002$ ) or on the street (AOR $1.46,95 \%$ CI 1.1 to $1.9 ; \mathrm{p}=0.003$ ), injecting with someone (AOR 1.42, 95\% CI 1.1 to $1.8 ; \mathrm{p}=0.006$ ), use of a professional injector at last injection (AOR $1.36,95 \%$ CI 1.1 to $1.7 ; \mathrm{p}=0.007$ ) and visiting a FSW in the last 6 months (AOR $1.37,95 \%$ CI 1.0 to $1.8 ; \mathrm{p}=0.033)$. Having more than a middle school education (vs being illiterate; AOR 0.66, 95\% CI 
Table 1 Socio-demographic, injection drug use, sexual behaviour and other characteristics of injection drug users in selected cities of Pakistan, 2006 (round 2) and 2011 (round 4)

\begin{tabular}{|c|c|c|c|c|c|c|c|c|c|c|c|c|c|c|}
\hline \multirow[b]{3}{*}{$\begin{array}{l}\text { Year of survey } \\
\text { Sample size }\end{array}$} & \multicolumn{4}{|c|}{ Punjab province } & \multicolumn{4}{|c|}{ Sindh province } & \multicolumn{4}{|c|}{ Other province } & & \\
\hline & \multicolumn{2}{|c|}{ Lahore } & \multicolumn{2}{|c|}{ Other Punjab } & \multicolumn{2}{|c|}{ Karachi } & \multicolumn{2}{|c|}{ Other Sindh } & \multicolumn{2}{|c|}{ Quetta } & \multicolumn{2}{|c|}{ Peshawar } & \multicolumn{2}{|c|}{ All cities } \\
\hline & $\begin{array}{l}2006 \\
(400) \\
(\%)\end{array}$ & $\begin{array}{l}2011 \\
(365) \\
(\%)\end{array}$ & $\begin{array}{l}2006 \\
(1200) \\
(\%)\end{array}$ & $\begin{array}{l}2011 \\
(1441) \\
(\%)\end{array}$ & $\begin{array}{l}2006 \\
(399) \\
(\%)\end{array}$ & $\begin{array}{l}2011 \\
(354) \\
(\%)\end{array}$ & $\begin{array}{l}2006 \\
(798) \\
(\%)\end{array}$ & $\begin{array}{l}2011 \\
(730) \\
(\%)\end{array}$ & $\begin{array}{l}2006 \\
(190) \\
(\%)\end{array}$ & $\begin{array}{l}2011 \\
(359) \\
(\%)\end{array}$ & $\begin{array}{l}2006 \\
(180) \\
(\%)\end{array}$ & $\begin{array}{l}2011 \\
(260)(\%)\end{array}$ & $\begin{array}{l}2006 \\
(3167) \\
(\%)\end{array}$ & $\begin{array}{l}2011 \\
(3509) \\
(\%)\end{array}$ \\
\hline HIV prevalence & 6.5 & $30.7 * * *$ & 21.5 & $42.1 * * *$ & 30.1 & $43.2^{* * *}$ & 10.9 & $18.9 * * *$ & 9.5 & 7.2 & 2.2 & $20 * * *$ & 16.2 & $31.0 * * *$ \\
\hline \multicolumn{15}{|c|}{ Used a dirty syringe, last injection } \\
\hline No & 92.0 & 58.1 & 68.3 & 54.7 & 91.1 & 79.4 & 49.6 & 71.4 & 82.3 & 61.6 & 90.5 & 60.3 & 71.6 & 62.1 \\
\hline Yes & 8.0 & $41.9 * * *$ & 31.7 & $45.3^{* * *}$ & 8.9 & $20.6^{* * *}$ & 50.4 & $28.6^{* * *}$ & 17.7 & $38.4^{* * *}$ & 9.5 & $39.7^{* * *}$ & 28.4 & $37.9^{* * *}$ \\
\hline \multicolumn{15}{|c|}{ Socio-demographic characteristics } \\
\hline \multicolumn{15}{|c|}{ Age group } \\
\hline$<20$ & 1.3 & 0.8 & 1.8 & 1.8 & 3.0 & 5.1 & 2.6 & 2.2 & 1.1 & 1.9 & 3.9 & 10.4 & 2.2 & 2.8 \\
\hline $20-24$ & 10.0 & 19.2 & 14.6 & 23.2 & 12.8 & 24.3 & 13.9 & 8.4 & 14.3 & 19.8 & 21.2 & 31.2 & 14.0 & 20.1 \\
\hline $25-29$ & 16.3 & 17.8 & 29.5 & 29.4 & 17.9 & 28.0 & 22.4 & 16.0 & 22.2 & 29.5 & 26.8 & 21.9 & 24.0 & 24.7 \\
\hline $30-34$ & 18.8 & 17.3 & 17.4 & 20.7 & 17.4 & 18.1 & 17.3 & 21.6 & 16.9 & 20.3 & 11.7 & 16.5 & 17.2 & 19.9 \\
\hline $35-39$ & 19.3 & 18.6 & 15.3 & 9.5 & 18.1 & 11.0 & 21.8 & 32.2 & 16.9 & 17.0 & 15.6 & 9.6 & 17.9 & 16.1 \\
\hline $40+$ & 34.5 & 26.3 & 21.4 & 15.3 & 30.7 & 13.6 & 22.0 & 19.6 & 28.6 & 11.4 & 20.7 & 10.4 & 24.8 & 16.4 \\
\hline Mean & 34.7 & 33.5 & 31.7 & 30.4 & 33.4 & 29.4 & 32.1 & 33.2 & 32.7 & 29.8 & 30.6 & 28.0 & 32.4 & 31.0 \\
\hline \multicolumn{15}{|l|}{ Education level } \\
\hline Illiterate & 64.8 & 57.3 & 62.0 & 59.9 & 59.5 & 61.5 & 51.5 & 50.8 & 49.2 & 18.7 & 64.2 & 45.4 & 58.7 & 52.6 \\
\hline $\begin{array}{l}\text { Primary school } \\
\text { only }\end{array}$ & 13.0 & 20.3 & 20.8 & 22.9 & 18.2 & 11.3 & 32.0 & 27.8 & 20.1 & 31.8 & 14.0 & 20.8 & 21.9 & 23.2 \\
\hline $\begin{array}{l}\text { Middle school } \\
\text { or more }\end{array}$ & 22.3 & 22.5 & 17.3 & 17.2 & 22.3 & 27.2 & 16.5 & 21.4 & 30.7 & 49.6 & 21.8 & 33.8 & 19.4 & 24.2 \\
\hline \multicolumn{15}{|l|}{ Marital status } \\
\hline Unmarried & 49.0 & 55.1 & 41.5 & 53.0 & 58.4 & 61.3 & 55.9 & 47.4 & 54.5 & 47.6 & 60.9 & 64.6 & 50.1 & 53.2 \\
\hline $\begin{array}{l}\text { Currently } \\
\text { married }\end{array}$ & 47.8 & 36.4 & 52.8 & 30.5 & 39.3 & 33.1 & 41.8 & 50.1 & 40.7 & 52.4 & 38.0 & 26.2 & 46.2 & 37.4 \\
\hline $\begin{array}{l}\text { Separated/ } \\
\text { divorced/ } \\
\text { widowed }\end{array}$ & 3.3 & 8.5 & 5.7 & 16.5 & 2.3 & 5.6 & 2.3 & 2.5 & 4.8 & 0.0 & 1.1 & 9.2 & 3.8 & 9.4 \\
\hline \multicolumn{15}{|c|}{ Place currently living } \\
\hline Home & 44.0 & 31.8 & 73.1 & 56.9 & 65.1 & 30.3 & 58.6 & 43.4 & 72.5 & 82.0 & 50.6 & 68.7 & 63.4 & 52.2 \\
\hline $\begin{array}{l}\text { Hostel/hotel, } \\
\text { etc }\end{array}$ & 24.5 & 19.2 & 14.7 & 14.4 & 10.6 & 2.0 & 17.6 & 13.4 & 14.3 & 5.9 & 12.2 & 14.5 & 16.0 & 12.6 \\
\hline Street/lane & 31.5 & 49.0 & 12.2 & 28.7 & 24.4 & 67.7 & 23.8 & 43.2 & 13.2 & 12.1 & 37.2 & 16.9 & 20.6 & 35.3 \\
\hline \multicolumn{15}{|c|}{ Who currently living with } \\
\hline Alone & 29.3 & 46.0 & 10.3 & 20.0 & 29.1 & 10.7 & 11.0 & 21.1 & 8.9 & 5.0 & 11.1 & 14.3 & 15.2 & 20.0 \\
\hline $\begin{array}{l}\text { Relatives/ } \\
\text { family }\end{array}$ & 43.0 & 30.7 & 74.8 & 56.5 & 57.1 & 32.8 & 54.8 & 42.9 & 71.6 & 79.9 & 51.1 & 64.5 & 62.0 & 51.6 \\
\hline Friends/other & 27.8 & 23.3 & 14.8 & 23.5 & 13.8 & 56.5 & 34.2 & 36.0 & 19.5 & 15.1 & 37.8 & 21.2 & 22.8 & 28.4 \\
\hline Injecting drug & & & & & & & & & & & & & & \\
\hline Duration of injecti & ng habit & & & & & & & & & & & & & \\
\hline 1 year or less & 9.8 & 15.3 & 12.8 & 21.0 & 7.6 & 18.4 & 10.3 & 2.2 & 14.4 & 16.8 & 52.5 & 25.1 & 13.5 & 16.1 \\
\hline $2-4$ years & 34.8 & 28.2 & 51.5 & 52.3 & 46.9 & 40.1 & 39.2 & 27.8 & 39.4 & 65.0 & 29.6 & 47.5 & 43.7 & 44.4 \\
\hline $5-9$ years & 35.0 & 31.5 & 25.0 & 20.8 & 29.5 & 26.3 & 29.5 & 32.8 & 26.6 & 15.7 & 11.2 & 20.4 & 27.3 & 24.4 \\
\hline $10+$ years & 20.5 & 24.9 & 10.7 & 6.0 & 16.1 & 15.3 & 20.9 & 37.2 & 19.7 & 2.5 & 6.7 & 7.1 & 15.5 & 15.1 \\
\hline How often inject $p$ & eer day, & st month & & & & & & & & & & & & \\
\hline Once a day & 4.0 & 6.0 & 6.8 & 2.4 & 10.6 & 1.4 & 9.2 & 8.4 & 34.4 & 13.9 & 23.6 & 39.2 & 10.1 & 7.8 \\
\hline $\begin{array}{l}\text { 2-3 times a } \\
\text { day }\end{array}$ & 69.8 & 62.7 & 66.6 & 68.0 & 72.2 & 79.7 & 78.6 & 74.9 & 58.2 & 67.4 & 64.4 & 52.3 & 70.1 & 68.9 \\
\hline $4+$ & 26.3 & 31.2 & 26.5 & 29.6 & 17.2 & 18.9 & 12.2 & 16.7 & 7.4 & 18.7 & 12.1 & 8.5 & 19.8 & 23.3 \\
\hline Always used clean & syringe, & ast month & & & & & & & & & & & & \\
\hline No & 56.9 & 72.8 & 56.4 & 78.5 & 16.4 & 46.3 & 85.5 & 80.7 & 44.4 & 95.2 & 31.2 & 73.7 & 56.7 & 76.5 \\
\hline Yes & 43.1 & 27.2 & 43.6 & 21.5 & 83.6 & 53.7 & 14.5 & 19.3 & 55.6 & 4.8 & 68.8 & 26.3 & 43.3 & 23.5 \\
\hline Injected by profess & sional inj & ctor, last m & onth & & & & & & & & & & & \\
\hline No & 97.0 & 32.7 & 58.2 & 21.7 & 90.2 & 30.2 & 83.2 & 42.0 & 85.3 & 53.7 & 55.2 & 32.2 & 74.8 & 31.9 \\
\hline Yes & 3.0 & 67.3 & 41.8 & 78.3 & 9.8 & 69.8 & 16.8 & 58.0 & 14.7 & 46.3 & 44.8 & 67.8 & 25.2 & 68.1 \\
\hline
\end{tabular}


Table 1 Continued

\begin{tabular}{|c|c|c|c|c|c|c|c|c|c|c|c|c|c|c|}
\hline \multirow[b]{3}{*}{ Year of survey } & \multicolumn{4}{|c|}{ Punjab province } & \multicolumn{4}{|c|}{ Sindh province } & \multicolumn{4}{|c|}{ Other province } & & \\
\hline & \multicolumn{2}{|c|}{ Lahore } & \multicolumn{2}{|c|}{ Other Punjab } & \multicolumn{2}{|c|}{ Karachi } & \multicolumn{2}{|c|}{ Other Sindh } & \multicolumn{2}{|c|}{ Quetta } & \multicolumn{2}{|c|}{ Peshawar } & \multicolumn{2}{|c|}{ All cities } \\
\hline & 2006 & 2011 & 2006 & 2011 & 2006 & 2011 & 2006 & 2011 & 2006 & 2011 & 2006 & 2011 & 2006 & 2011 \\
\hline Sample size & $\begin{array}{l}(400) \\
(\%)\end{array}$ & $\begin{array}{l}(365) \\
(\%)\end{array}$ & $\begin{array}{l}(1200) \\
(\%)\end{array}$ & $\begin{array}{l}(1441) \\
(\%)\end{array}$ & $\begin{array}{l}(399) \\
(\%)\end{array}$ & $\begin{array}{l}(354) \\
(\%)\end{array}$ & $\begin{array}{l}(798) \\
(\%)\end{array}$ & $\begin{array}{l}(730) \\
(\%)\end{array}$ & $\begin{array}{l}(190) \\
(\%)\end{array}$ & $\begin{array}{l}(359) \\
(\%)\end{array}$ & $\begin{array}{l}(180) \\
(\%)\end{array}$ & $(260)(\%)$ & $\begin{array}{l}(3167) \\
(\%)\end{array}$ & $\begin{array}{l}(3509) \\
(\%)\end{array}$ \\
\hline \multicolumn{15}{|c|}{ Frequency of injection, yesterday } \\
\hline 0 times & 3.8 & 0.8 & 25.0 & 0.5 & 22.0 & 1.1 & 0.9 & 0.4 & 11.9 & 0.6 & 19.8 & 1.9 & 14.7 & 0.7 \\
\hline 1-2 time & 50.5 & 34.5 & 36.6 & 33.1 & 50.1 & 44.4 & 48.6 & 22.5 & 75.1 & 53.5 & 49.7 & 70.4 & 46.1 & 37.0 \\
\hline $3+$ times & 45.8 & 64.7 & 38.4 & 66.4 & 27.8 & 54.5 & 50.5 & 77.1 & 13.0 & 46.0 & 30.5 & 27.7 & 39.2 & 62.3 \\
\hline \multicolumn{15}{|c|}{ Where you last injected } \\
\hline $\begin{array}{l}\text { Non-public } \\
\text { space }\end{array}$ & 26.1 & 8.8 & 31.8 & 14.0 & 8.2 & 1.1 & 53.0 & 18.2 & 13.3 & 13.1 & 19.8 & 26.5 & 31.7 & 13.9 \\
\hline Public space & 73.9 & 91.2 & 68.2 & 86.0 & 91.8 & 98.9 & 47.0 & 81.8 & 86.7 & 86.9 & 80.2 & 73.5 & 68.3 & 86.1 \\
\hline \multicolumn{15}{|c|}{ Who you last injected with } \\
\hline No one & 60.0 & 34.5 & 21.4 & 26.2 & 26.7 & 5.6 & 33.0 & 20.7 & 42.3 & 22.6 & 27.5 & 16.2 & 31.5 & 22.7 \\
\hline $\begin{array}{l}\text { Somebody } \\
\text { else }\end{array}$ & 40.0 & 65.5 & 78.6 & 73.8 & 73.3 & 94.4 & 67.0 & 79.3 & 57.7 & 77.4 & 72.5 & 83.8 & 68.5 & 77.3 \\
\hline \multicolumn{15}{|c|}{ Professional injector, last injection } \\
\hline No & 94.5 & 60.3 & 83.5 & 56.8 & 94.7 & 46.3 & 93.9 & 77.4 & 91.0 & 80.4 & 78.7 & 74.8 & 89.1 & 64.1 \\
\hline Yes & 5.5 & 39.7 & 16.5 & 43.2 & 5.3 & 53.7 & 6.1 & 22.6 & 9.0 & 19.6 & 21.3 & 25.2 & 10.9 & 35.9 \\
\hline \multicolumn{15}{|l|}{ Inject avil } \\
\hline No & 15.5 & 2.7 & 28.7 & 12.5 & 10.5 & 1.4 & 7.0 & 15.3 & 44.2 & 18.9 & 5.0 & 5.0 & 18.9 & 11.1 \\
\hline Yes & 84.5 & 97.3 & 71.3 & 87.5 & 89.5 & 98.6 & 93.0 & 84.7 & 55.8 & 81.1 & 95.0 & 95.0 & 81.1 & 88.9 \\
\hline Inject heroin & & & & & & & & & & & & & & \\
\hline No & 86.5 & 69.3 & 66.2 & 20.9 & 23.8 & 3.1 & 40.5 & 12.9 & 23.7 & 18.9 & 83.9 & 90.8 & 55.4 & 27.4 \\
\hline Yes & 13.5 & 30.7 & 33.8 & 79.1 & 76.2 & 96.9 & 59.5 & 87.1 & 76.3 & 81.1 & 16.1 & 9.2 & 44.6 & 72.6 \\
\hline Inject diazepam & & & & & & & & & & & & & & \\
\hline No & 30.0 & 19.5 & 64.8 & 83.8 & 85.2 & 94.9 & 68.2 & 92.6 & 87.9 & 57.7 & 96.7 & 71.5 & 67.0 & 76.5 \\
\hline Yes & 70.0 & 80.5 & 35.2 & 16.2 & 14.8 & 5.1 & 31.8 & 7.4 & 12.1 & 42.3 & 3.3 & 28.5 & 33.0 & 23.5 \\
\hline Inject tamgesic & & & & & & & & & & & & & & \\
\hline No & 36.3 & 42.5 & 65.3 & 87.0 & 81.0 & 100.0 & 88.2 & 99.3 & 94.2 & 99.4 & 99.4 & 86.9 & 73.0 & 87.5 \\
\hline Yes & 63.7 & 57.5 & 34.8 & 13.0 & 19.0 & 0.0 & 11.8 & 0.7 & 5.8 & 0.6 & 0.6 & 13.1 & 27.0 & 12.5 \\
\hline Sexual behaviours & & & & & & & & & & & & & & \\
\hline Age at first sex & & & & & & & & & & & & & & \\
\hline $10-14$ & 17.9 & 19.2 & 11.9 & 14.7 & 7.3 & 26.3 & 1.6 & 20.4 & 7.3 & 1.3 & 10.4 & 16.5 & 9.9 & 16.2 \\
\hline $15-19$ & 54.5 & 62.8 & 61.5 & 59.8 & 44.1 & 55.2 & 64.1 & 65.8 & 31.8 & 44.6 & 68.8 & 45.1 & 58.9 & 58.4 \\
\hline $20+$ & 27.6 & 18.0 & 26.5 & 25.5 & 48.6 & 18.4 & 34.3 & 13.8 & 60.9 & 54.2 & 20.8 & 38.3 & 31.2 & 25.4 \\
\hline Paid FSW for se & last $6 \mathrm{~m}$ & ths & & & & & & & & & & & & \\
\hline No & 78.4 & 82.4 & 69.0 & 81.7 & 75.9 & 95.5 & 90.6 & 80.3 & 90.2 & 46.0 & 82.6 & 80.1 & 77.6 & 79.3 \\
\hline Yes & 21.6 & 17.6 & 31.0 & 18.3 & 24.1 & 4.5 & 9.4 & 19.7 & 9.8 & 54.0 & 17.4 & 19.9 & 22.4 & 20.7 \\
\hline Used condom at & st paid & $x$ with & & & & & & & & & & & & \\
\hline No & 57.8 & 74.1 & 86.1 & 83.8 & 72.7 & 37.5 & 94.4 & 57.1 & 97.9 & 85.1 & 73.1 & 84.0 & 85.3 & 76.8 \\
\hline Yes & 42.2 & 25.9 & 13.9 & 16.3 & 27.3 & 62.5 & 5.6 & 42.9 & 2.1 & 14.9 & 26.9 & 16.0 & 14.7 & 23.2 \\
\hline Paid MSW/HSW & r sex, la & 6 mont & & & & & & & & & & & & \\
\hline No & 86.8 & 92.3 & 81.1 & 92.4 & 91.4 & 97.7 & 93.3 & 84.3 & 93.1 & 89.4 & 86.5 & 90.6 & 87.2 & 90.8 \\
\hline Yes & 13.3 & 7.7 & 18.9 & 7.6 & 8.6 & 2.3 & 6.7 & 15.7 & 6.9 & 10.6 & 13.5 & 9.4 & 12.8 & 9.2 \\
\hline Used condom a & ast sex $v$ & h MSW & & & & & & & & & & & & \\
\hline No & 75.0 & 76.0 & 93.2 & 83.6 & 76.5 & 71.4 & 98.1 & 77.4 & 92.9 & 83.8 & 60.0 & 87.0 & 88.0 & 80.8 \\
\hline Yes & 25.0 & 24.0 & 6.8 & 16.4 & 23.5 & 28.6 & 1.9 & 22.6 & 7.1 & 16.2 & 40.0 & 13.0 & 12.0 & 19.2 \\
\hline Exchanged sex & money/ & & & & & & & & & & & & & \\
\hline No & 75.1 & 73.8 & 88.3 & 83.1 & 92.9 & 93.8 & 72.2 & 92.2 & 94.2 & 85.8 & 87.1 & 89.4 & 83.5 & 85.8 \\
\hline Yes & 24.9 & 26.2 & 11.7 & 16.9 & 7.1 & 6.2 & 27.8 & 7.8 & 5.8 & 14.2 & 12.9 & 10.6 & 16.5 & 14.2 \\
\hline Awareness of gc & rnment & ogramn & for IDU & & & & & & & & & & & \\
\hline No & 70.5 & 94.8 & 66.2 & 83.8 & 70.2 & 15.6 & 68.3 & 77.6 & 67.9 & 18.3 & 61.2 & 93.0 & 67.6 & 70.8 \\
\hline Yes & 29.5 & 5.2 & 33.8 & 16.2 & 29.8 & 84.4 & 31.7 & 22.4 & 32.1 & 81.7 & 38.8 & 7.0 & 32.4 & 29.2 \\
\hline
\end{tabular}

${ }^{*} \mathrm{p}<0.05 ;{ }^{* *} \mathrm{p}<.01 ;{ }^{* * *} \mathrm{p}<0.0001$, based on $\chi^{2}$ tests of association.

Because of multiple comparisons ( $n=7)$, and using the Bonferonni correction, $p<0.007$ was considered statistically significant at the $95 \% \mathrm{Cl}$ level.

FSW, female sex worker; HSW, hijra sex worker; IDU, injecting drug user; MSW, male sex worker. 
Table 2 Association between socio-demographic, injecting drug use, sexual behaviour and other characteristics, and HIV, use of used syringes (at last injection), and use of a professional injector (last injection) among injection drug users in Punjab, 2011* $\dagger$

\begin{tabular}{|c|c|c|c|c|c|c|}
\hline & \multicolumn{2}{|l|}{ HIV } & \multicolumn{2}{|c|}{ Used dirty syringe, last injection } & \multicolumn{2}{|c|}{$\begin{array}{l}\text { Used professional injector, last } \\
\text { injection }\end{array}$} \\
\hline & Adjusted OR $(95 \% \mathrm{Cl})$ & p Value & Adjusted OR (95\% Cl) & $p$ Value & Adjusted OR (95\% Cl) & p Value \\
\hline \multicolumn{7}{|l|}{ Age group } \\
\hline$<20$ & Ref & & Ref & & Ref & \\
\hline $20-24$ & 1.56 (0.64 to 3.77$)$ & 0.324 & 0.78 (0.32 to 1.86$)$ & 0.569 & $0.63(0.25$ to 1.58$)$ & 0.325 \\
\hline $25-29$ & 1.31 (0.54 to 3.18 ) & 0.547 & 0.73 (0.30 to 1.74$)$ & 0.477 & $0.56(0.22$ to 1.40$)$ & 0.213 \\
\hline $30-34$ & $1.23(0.50$ to 3.03$)$ & 0.649 & 0.95 (0.39 to 2.30$)$ & 0.904 & 0.51 (0.20 to 1.29$)$ & 0.157 \\
\hline $35-39$ & 0.87 (0.34 to 2.20$)$ & 0.764 & 0.82 (0.33 to 2.06$)$ & 0.677 & $0.65(0.25$ to 1.70$)$ & 0.381 \\
\hline $40+$ & $0.76(0.30$ to 1.91$)$ & 0.563 & 0.64 (0.26 to 1.57$)$ & 0.327 & 0.65 (0.25 to 1.68$)$ & 0.374 \\
\hline \multicolumn{7}{|l|}{ Education } \\
\hline Illiterate & Ref & & Ref & & Ref & \\
\hline Primary school only & $0.68(0.53$ to 0.89$)$ & 0.004 & $0.87(0.68$ to 1.12$)$ & 0.277 & $0.90(0.69$ to 1.18$)$ & 0.455 \\
\hline Middle school or more & 0.84 (0.63 to 1.11$)$ & 0.212 & 0.66 (0.50 to 0.87 ) & 0.003 & 0.85 (0.63 to 1.14$)$ & 0.276 \\
\hline \multicolumn{7}{|l|}{ Marital status } \\
\hline Unmarried & Ref & & Ref & & Ref & \\
\hline Currently married & 0.79 (0.61 to 1.01$)$ & 0.064 & $0.93(0.73$ to 1.20$)$ & 0.579 & $0.93(0.71$ to 1.21$)$ & 0.573 \\
\hline Separated/divorced & 0.71 (0.51 to 0.98 ) & 0.037 & 0.93 (0.68 to 1.27 ) & 0.665 & 0.80 (0.57 to 1.12$)$ & 0.192 \\
\hline \multicolumn{7}{|l|}{ Where living } \\
\hline Home & Ref & & Ref & & Ref & \\
\hline Hostel/hotel, etc & $0.68(0.49$ to 0.94$)$ & 0.020 & 1.63 (1.19 to 2.22$)$ & 0.002 & $0.86(0.61$ to 1.21$)$ & 0.397 \\
\hline Street/lane, etc & 0.81 (0.63 to 1.04 ) & 0.092 & 1.46 (1.14 to 1.86$)$ & 0.003 & 1.36 (1.05 to 1.77$)$ & 0.021 \\
\hline \multicolumn{7}{|l|}{ Duration of injecting habit } \\
\hline 1 year or less & Ref & & Ref & & Ref & \\
\hline $2-4$ years & 1.49 (1.12 to 1.98$)$ & 0.006 & 0.95 (0.72 to 1.25$)$ & 0.698 & $0.78(0.58$ to 1.05$)$ & 0.096 \\
\hline $5-9$ years & 1.61 (1.14 to 2.27$)$ & 0.007 & 0.71 (0.51 to 0.98$)$ & 0.040 & 0.69 (0.48 to 0.98$)$ & 0.038 \\
\hline $10+$ years & 1.35 (0.86 to 2.13$)$ & 0.194 & 0.73 (0.47 to 1.12 ) & 0.147 & $0.73(0.46$ to 1.17$)$ & 0.193 \\
\hline \multicolumn{7}{|c|}{ Frequency of injection, yesterday } \\
\hline 0 times & Ref & & Ref & & Ref & \\
\hline $1-2$ times & $0.43(0.11$ to 1.73$)$ & 0.236 & 2.24 (0.45 to 11.14$)$ & 0.326 & 0.69 (0.16 to 3.04$)$ & 0.628 \\
\hline $3+$ times & 0.72 (0.18 to 2.86$)$ & 0.642 & 1.83 (0.37 to 9.08$)$ & 0.460 & $0.71(0.16$ to 3.11$)$ & 0.653 \\
\hline \multicolumn{7}{|l|}{ Where last injected } \\
\hline Non-public space & Ref & & Ref & & Ref & \\
\hline Public space & 0.86 (0.63 to 1.18$)$ & 0.349 & 0.89 (0.65 to 1.21$)$ & 0.448 & $1.19(0.84$ to 1.68$)$ & 0.335 \\
\hline \multicolumn{7}{|l|}{ Who last injected with } \\
\hline Nobody & Ref & & Ref & & Ref & \\
\hline Someone else & 0.88 (0.69 to 1.14$)$ & 0.340 & 1.42 (1.11 to 1.82$)$ & 0.006 & 7.32 (5.40 to 9.91$)$ & 0.000 \\
\hline \multicolumn{7}{|c|}{ Used dirty syringe, last injection } \\
\hline No & Ref & & - & - & Ref & \\
\hline Yes & 0.98 (0.79 to 1.21$)$ & 0.839 & - & - & 1.35 (1.08 to 1.68$)$ & 0.008 \\
\hline \multicolumn{7}{|c|}{ Used a professional injector, last injection } \\
\hline No & Ref & & Ref & & - & - \\
\hline Yes & 1.14 (0.91 to 1.43$)$ & 0.257 & $1.36(1.09$ to 1.69$)$ & 0.007 & - & - \\
\hline \multicolumn{7}{|l|}{ Injected avil } \\
\hline No & Ref & & Ref & & Ref & \\
\hline Yes & 0.59 (0.42 to 0.82$)$ & 0.002 & 1.04 (0.74 to 1.46$)$ & 0.829 & $0.95(0.66$ to 1.36$)$ & 0.764 \\
\hline \multicolumn{7}{|l|}{ Injected heroin } \\
\hline No & Ref & & Ref & & Ref & \\
\hline Yes & $0.90(0.69$ to 1.17$)$ & 0.430 & $1.28(0.98$ to 1.66$)$ & 0.066 & $1.01(0.77$ to 1.34$)$ & 0.921 \\
\hline \multicolumn{7}{|l|}{ Injected diazepam } \\
\hline No & Ref & & Ref & & Ref & \\
\hline Yes & $0.62(0.46$ to 0.83$)$ & 0.002 & $1.20(0.90$ to 1.61$)$ & 0.206 & $0.82(0.60$ to 1.12$)$ & 0.207 \\
\hline \multicolumn{7}{|l|}{ Injected tamgesic } \\
\hline No & Ref & & Ref & & Ref & \\
\hline Yes & 1.04 (0.77 to 1.42$)$ & 0.788 & 1.02 (0.76 to 1.37$)$ & 0.902 & $1.15(0.84$ to 1.58$)$ & 0.385 \\
\hline Paid FSW, last 6 months & & & & & & \\
\hline No & Ref & & Ref & & Ref & \\
\hline Yes & $0.90(0.67$ to 1.20$)$ & 0.460 & 1.37 (1.03 to 1.82$)$ & 0.033 & $0.82(0.60$ to 1.12$)$ & 0.216 \\
\hline
\end{tabular}


Table 2 Continued

\begin{tabular}{|c|c|c|c|c|c|c|}
\hline & \multicolumn{2}{|l|}{ HIV } & \multicolumn{2}{|c|}{ Used dirty syringe, last injection } & \multicolumn{2}{|c|}{$\begin{array}{l}\text { Used professional injector, last } \\
\text { injection }\end{array}$} \\
\hline & Adjusted OR (95\% Cl) & $p$ Value & Adjusted OR (95\% Cl) & $p$ Value & Adjusted OR (95\% Cl) & $p$ Value \\
\hline \multicolumn{7}{|c|}{ Paid MSW/HSW for sex, last 6 months } \\
\hline No & Ref & & & & & \\
\hline Yes & $0.80(0.53$ to 1.21$)$ & 0.285 & $1.03(0.70$ to 1.54$)$ & 0.868 & 0.94 (0.61 to 1.44$)$ & 0.764 \\
\hline \multicolumn{7}{|c|}{ Has done sex work } \\
\hline No & Ref & & Ref & & Ref & \\
\hline Yes & 1.07 (0.81 to 1.42$)$ & 0.616 & $1.15(0.87$ to 1.51$)$ & 0.321 & $1.01(0.76$ to 1.35$)$ & 0.939 \\
\hline \multicolumn{7}{|c|}{ Aware of Government of Pakistan IDU services } \\
\hline No & Ref & & Ref & & Ref & \\
\hline Yes & $1.17(0.86$ to 1.58$)$ & 0.320 & $0.70(0.52$ to 0.96$)$ & 0.024 & 2.14 (1.55 to 2.97$)$ & 0.000 \\
\hline
\end{tabular}

Table 3 Association between socio-demographic, injecting drug use, sexual behaviour and other characteristics, and HIV, use of used syringes (at last injection), and use of a professional injector (last injection) among injection drug users in Sindh, $2011^{*} \dagger$

\begin{tabular}{|c|c|c|c|c|c|c|}
\hline & \multicolumn{2}{|l|}{ HIV } & \multicolumn{2}{|c|}{ Used dirty syringe, last injection } & \multicolumn{2}{|c|}{$\begin{array}{l}\text { Used professional injector, last } \\
\text { injection }\end{array}$} \\
\hline & Adjusted OR (95\% Cl) & $\mathrm{p}$ Value & Adjusted OR (95\% Cl) & $\mathrm{p}$ Value & Adjusted OR $(95 \% \mathrm{Cl})$ & $\mathrm{p}$ Value \\
\hline \multicolumn{7}{|l|}{ Age group } \\
\hline$<20$ & Ref & & Ref & & Ref & \\
\hline $20-24$ & $0.58(0.24$ to 1.37$)$ & 0.212 & 0.68 (0.27 to 1.74$)$ & 0.423 & 0.90 (0.37 to 2.20$)$ & 0.824 \\
\hline $25-29$ & $0.50(0.21$ to 1.17$)$ & 0.110 & 0.66 (0.27 to 1.64$)$ & 0.374 & 0.61 (0.25 to 1.47 ) & 0.270 \\
\hline $30-34$ & $0.50(0.21$ to 1.18$)$ & 0.114 & 1.06 (0.42 to 2.64$)$ & 0.909 & 0.51 (0.21 to 1.24 ) & 0.138 \\
\hline $35-39$ & 0.27 (0.11 to 0.66$)$ & 0.004 & 1.27 (0.50 to 3.22 ) & 0.616 & 0.56 (0.23 to 1.40$)$ & 0.216 \\
\hline $40+$ & 0.21 (0.08 to 0.54$)$ & 0.001 & 1.24 (0.47 to 3.28 ) & 0.667 & 0.55 (0.21 to 1.41$)$ & 0.213 \\
\hline \multicolumn{7}{|l|}{ Education } \\
\hline Illiterate & Ref & & Ref & & Ref & \\
\hline Primary school only & 0.85 (0.57 to 1.28$)$ & 0.443 & 1.22 (0.82 to 1.82 ) & 0.316 & 0.93 (0.62 to 1.40$)$ & 0.734 \\
\hline Middle school or more & 0.87 (0.59 to 1.27$)$ & 0.471 & 0.72 (0.48 to 1.09 ) & 0.120 & 1.39 (0.96 to 2.01$)$ & 0.080 \\
\hline \multicolumn{7}{|l|}{ Marital } \\
\hline Unmarried & Ref & & Ref & & Ref & \\
\hline Currently married & $0.80(0.56$ to 1.16$)$ & 0.241 & 0.60 (0.41 to 0.87 ) & 0.007 & 0.79 (0.55 to 1.13$)$ & 0.188 \\
\hline Separated/divorced & 2.36 (1.08 to 5.14$)$ & 0.030 & 1.14 (0.51 to 2.54$)$ & 0.747 & 3.80 (1.59 to 9.04$)$ & 0.003 \\
\hline \multicolumn{7}{|l|}{ Where living } \\
\hline Home & Ref & & Ref & & Ref & \\
\hline Hostel/hotel, etc & $0.67(0.34$ to 1.31$)$ & 0.245 & 1.59 (0.89 to 2.85$)$ & 0.117 & 1.26 (0.69 to 2.28$)$ & 0.452 \\
\hline Street/lane, etc & 1.45 (1.02 to 2.06$)$ & 0.039 & $1.06(0.74$ to 1.53$)$ & 0.743 & 0.99 (0.70 to 1.41$)$ & 0.974 \\
\hline \multicolumn{7}{|l|}{ Duration of injecting habit } \\
\hline 1 year or less & Ref & & Ref & & Ref & \\
\hline 2 years & 1.19 (0.67 to 2.11$)$ & 0.559 & 1.50 (0.77 to 2.94$)$ & 0.235 & 0.60 (0.34 to 1.04$)$ & 0.070 \\
\hline $5-9$ years & $1.32(0.73$ to 2.39$)$ & 0.359 & $1.07(0.54$ to 2.15$)$ & 0.841 & 0.57 (0.32 to 1.01$)$ & 0.054 \\
\hline $10+$ years & $0.98(0.51$ to 1.88$)$ & 0.953 & 0.84 (0.40 to 1.76$)$ & 0.653 & 0.24 (0.13 to 0.45$)$ & 0.000 \\
\hline \multicolumn{7}{|c|}{ Frequency of injection, yesterday } \\
\hline 0 times & Ref & & Ref & & Ref & \\
\hline $1-2$ times & 0.81 (0.13 to 4.84$)$ & 0.813 & 0.90 (0.14 to 5.81$)$ & 0.909 & $4.88(0.40$ to 58.97$)$ & 0.213 \\
\hline $3+$ times & $0.80(0.13$ to 4.76$)$ & 0.804 & $1.55(0.24$ to 9.88$)$ & 0.645 & $3.40(0.28$ to 41.02$)$ & 0.336 \\
\hline \multicolumn{7}{|l|}{ Where last injected } \\
\hline Non-public space & Ref & & Ref & & Ref & \\
\hline Public space & $1.51(0.85$ to 2.70$)$ & 0.161 & $1.72(1.02$ to 2.90$)$ & 0.042 & 0.57 (0.33 to 0.98$)$ & 0.042 \\
\hline \multicolumn{7}{|l|}{ Who last injected with } \\
\hline Nobody & Ref & & Ref & & Ref & \\
\hline Someone else & $0.78(0.46$ to 1.32$)$ & 0.354 & $0.26(0.16$ to 0.43$)$ & 0.000 & 9.59 (4.63 to 19.86$)$ & 0.000 \\
\hline
\end{tabular}


Table 3 Continued

\begin{tabular}{|c|c|c|c|c|c|c|}
\hline & \multicolumn{2}{|l|}{ HIV } & \multicolumn{2}{|c|}{ Used dirty syringe, last injection } & \multicolumn{2}{|c|}{$\begin{array}{l}\text { Used professional injector, last } \\
\text { injection }\end{array}$} \\
\hline & Adjusted OR (95\% Cl) & p Value & Adjusted OR (95\% Cl) & $\mathrm{p}$ Value & Adjusted OR (95\% Cl) & p Value \\
\hline \multicolumn{7}{|c|}{ Used dirty syringe, last injection } \\
\hline No & Ref & & - & - & Ref & \\
\hline Yes & $1.08(0.76$ to 1.55$)$ & 0.664 & - & - & $1.06(0.74$ to 1.53$)$ & 0.739 \\
\hline \multicolumn{7}{|c|}{ Used a professional injector, last injection } \\
\hline No & Ref & & Ref & & - & - \\
\hline Yes & $1.22(0.87$ to 1.73$)$ & 0.253 & 1.09 (0.76 to 1.57$)$ & 0.648 & - & - \\
\hline \multicolumn{7}{|c|}{ Injected avil } \\
\hline No & Ref & & Ref & & Ref & \\
\hline Yes & 0.65 (0.37 to 1.14$)$ & 0.132 & 2.65 (1.31 to 5.37$)$ & 0.007 & 1.75 (0.95 to 3.26$)$ & 0.075 \\
\hline \multicolumn{7}{|c|}{ Injected heroin } \\
\hline No & Ref & & Ref & & Ref & \\
\hline Yes & 1.48 (0.80 to 2.72$)$ & 0.208 & 0.83 (0.47 to 1.45$)$ & 0.511 & 1.03 (0.51 to 2.08$)$ & 0.938 \\
\hline \multicolumn{7}{|c|}{ Injected diazepam } \\
\hline No & Ref & & Ref & & Ref & \\
\hline Yes & 0.69 (0.35 to 1.36$)$ & 0.289 & 0.95 (0.48 to 1.86$)$ & 0.877 & 2.58 (1.44 to 4.59$)$ & 0.001 \\
\hline \multicolumn{7}{|c|}{ Injected tamgesic } \\
\hline No & Ref & & Ref & & - & - \\
\hline Yes & $5.20(0.64$ to 42.44$)$ & 0.124 & $2.46(0.27$ to 22.43$)$ & 0.426 & - & - \\
\hline \multicolumn{7}{|c|}{ Paid FSW, last 6 months } \\
\hline No & Ref & & Ref & & Ref & \\
\hline Yes & 0.90 (0.52 to 1.54$)$ & 0.696 & 1.29 (0.80 to 2.09$)$ & 0.303 & 0.57 (0.34 to 0.98$)$ & 0.040 \\
\hline \multicolumn{7}{|c|}{ Paid MSW/HSW for sex, last 6 months } \\
\hline No & Ref & & Ref & & & \\
\hline Yes & 0.67 (0.39 to 1.18 ) & 0.167 & 1.89 (1.17 to 3.07$)$ & 0.010 & 0.92 (0.55 to 1.56$)$ & 0.765 \\
\hline \multicolumn{7}{|c|}{ Has done sex work } \\
\hline No & Ref & & Ref & & Ref & \\
\hline Yes & 2.25 (1.19 to 4.25$)$ & 0.013 & $1.25(0.67$ to 2.35$)$ & 0.478 & 2.02 (1.06 to 3.82$)$ & 0.032 \\
\hline \multicolumn{7}{|c|}{ Aware of Government of Pakistan IDU services } \\
\hline No & Ref & & Ref & & Ref & \\
\hline Yes & 1.59 (1.12 to 2.24$)$ & 0.009 & $1.25(0.88$ to 1.79$)$ & 0.217 & $1.30(0.93$ to 1.83$)$ & 0.123 \\
\hline
\end{tabular}

0.5 to $0.9 ; \mathrm{p}=0.003$ ) and being aware of IDU services (AOR $0.7,95 \%$ CI 0.5 to $1.0 ; p=0.024$ ) were associated with a lower likelihood of reporting using a dirty syringe. In comparison, variables positively associated with use of a dirty syringe among IDUs from Sindh included injecting in a public space (AOR 1.72, 95\% CI 1.0 to 2.9; $\mathrm{p}=0.042$ ), injecting avil (AOR $2.65,95 \%$ CI 1.3 to $5.4 ; \mathrm{p}=0.007$ ), and paying for sex with a MSW/HSW in the past 6 months (AOR 1.89, 95\% CI 1.2 to $3.1 ; \mathrm{p}=0.010)$.

Factors associated with professional injector use at last injection for IDUs from Punjab and Sindh provinces are included in tables 2 and 3, respectively. For Punjab IDUs, variables positively associated with use of a professional injector at last injection include living on the streets (vs at home; AOR 1.36, 95\% CI 1.1 to $1.8 ; \mathrm{p}=0.021)$, injecting with someone else at last injection (vs alone; AOR 7.32, 95\% CI 5.4 to 9.9; $p<0.001$ ), use of a dirty syringe at last injection (AOR 1.35, 95\% CI 1.1 to $1.7 ; \mathrm{p}=0.008$ ) and being aware of IDU services (AOR 2.14, $95 \%$ CI 1.6 to $3.0 ; \mathrm{p}<0.001)$. For IDUs from Sindh, variables positively associated with use of a professional injector included being separated/divorced (vs being unmarried; AOR 3.8, 95\% CI 1.6 to $9.0 ; p=0.003)$, injecting with someone else at last injection (vs alone; AOR 9.59, 95\% CI 4.6 to 19.9 ; $\mathrm{p}<0.001$ ) and injecting diazepam (AOR 2.58, 95\% CI 1.4 to 4.6; $\mathrm{p}=0.001)$.

\section{DISCUSSION}

The IDU populations in cities across Pakistan illustrate a great deal of heterogeneity in terms of their injection and sexual risk profiles and their healthcare-seeking behaviours. This study's most salient finding is that HIV prevalence among IDUs in Pakistan increased dramatically between 2006 and 2011. This increase was observed in all geographical areas except Quetta, and was especially marked in Lahore (from $6.5 \%$ to $30.7 \%$ ) and Peshawar (from $2.2 \%$ to $20 \%$ ). It is not known whether this change represents an actual change in HIV prevalence in the IDU population or whether different subpopulations of IDUs participated in different rounds of the study, the latter explanation always being a possibility in hard-to-reach, marginalised populations such as IDUs, despite the sampling methods being the same in the two rounds. This highlights the importance of data triangulation and the use of data from other sources, including programmatic data, to help verify and explain results. However, since the sampling methods were refined within cities to suit the local needs of mapping and the involvement of social mobilisers, we feel the temporal trends within 
individual cities are more reliable than inter-city comparisons of temporal trends, and therefore that these observed increases likely represent genuine increases in HIV prevalence in IDU populations in Pakistan.

The multivariable analyses of factors associated with HIV infection in the provinces of Punjab and Sindh did not identify a common set of variables related to HIV infection, and this may have been due to the underlying heterogeneity of the IDU population between cities. In Punjab, HIV was associated with a longer duration of injecting behaviour, as might be expected, but this association was not observed in Sindh. In contrast, in Sindh there was an association between HIV and living on the street which is generally associated with a more chaotic, risky lifestyle. Overall during this time period, there was a general increase observed in the prevalence of most risk behaviours; in particular, larger proportions of IDUs reported injecting several times a day and using professional injectors, fewer IDUs reported always using clean syringes, and an increased proportion reported living on the street. In addition, during this period of 2006-2011, available anecdotal evidence points to a reduction in the availability of services for IDUs. We do not have any direct measures to support these anecdotal observations, but we did observe that awareness among participants of government programmes for IDUs declined overall from 32.4\% in 2006 to $29.2 \%$ in $2011(\mathrm{p}<0.01)$ and decreased in all geographical jurisdictions except Karachi and Quetta. Therefore, the findings of this study demonstrate increasing HIV prevalence and increasing risk behaviours among IDUs across Pakistan during a time in which the awareness and availability of services for IDUs were decreasing.

The data on risk behaviours presented in this report have the potential to guide the design and distribution of HIV prevention and care services for IDUs, and the need for such services is clearly demonstrated by the observed trend of increasing HIV prevalence. The frequent use of professional injectors by IDUs observed in this study was an unanticipated risk behaviour and this information will help guide programmes to improve the targeting and content of local HIV prevention and education activities, and in some circumstances may also encourage public health authorities to work with professional injectors as part of harm reduction initiatives. In addition, the results of this study will impact the development of intervention programmes for IDUs by linking the geographical mapping data of IDU populations and their risk behaviours to the distribution of services provided within a given city. Since at least some IDUs are obtaining a significant proportion of their illicit drugs from pharmacies, intervention initiatives involving pharmacies would also be helpful. Our results are consistent with IDU studies conducted in Chennai, India, where a significant proportion of IDUs obtained their syringes and their injectable drugs from pharmacies. $^{20}$ The recommendation by Solomon et al ${ }^{20}$ from this study was to coordinate efforts of pharmacies and syringe exchange programmes in high-prevalence areas for better coverage of IDUs. The ultimate impact of injectable prescription drugs on the HIV epidemic in Pakistan is currently unknown and should be a further avenue for research, given the widespread availability of prescription drugs (vs heroin and other illicit drugs). Evidence from developed countries suggest heroin injectors who also inject prescription drugs view their risk of HIV as lower than other heroin injectors. ${ }^{21}$

Finally, it should be noted that investigations by other members of the Canada-Pakistan HIV/AIDS Surveillance Project (HASP) team have demonstrated considerable geographical heterogeneity in terms of the types and prevalence of interactions between IDUs and other key populations at greater risk for HIV in Pakistan. The data suggest substantial sexual and drug injection bridging between IDUs and HSWs in Karachi and Larkana and FSWs in Lahore and Faisalabad, and sexual bridging also occurs between IDUs and HSWs in Faisalabad (Reza et al, in preparation for this special supplement). Quetta has the most significant bridging of all cities, with 16\%, 17\% and $30 \%$ MSWs, HSWs and FSWs, respectively, reporting sexual contact with IDUs and $3.8-7 \%$ injecting drugs (Reza et al). The intermingling between at least two high-risk groups gives rise to the potential for a wider spread of HIV in Pakistan. This situation mirrors that of China at the turn of the twentieth century, which saw its HIV epidemic spread from IDUs to commercial sex workers, transitioning from a truncated epidemic to one that is currently more generalised. ${ }^{22}$

There are a number of limitations that should be considered when interpreting the findings in this study. The mapping and recruitment methods used were rapid and relied on information from key informants, an approach that is most useful when strong prevention programmes are in place since they increase the availability and knowledge of key informants and other community members. However, few cities had well developed services for IDUs and so the mapping/recruitment process may have missed important pockets of IDUs, particularly more hidden groups that were therefore likely underrepresented in this study. Self-reported behaviours are known to be prone to biases based on social desirability and people exposed to education programmes may be more likely to report lower levels of risk behaviour than those not exposed to programmes. Since exposure to programmes in Pakistan was highly variable (and generally low), some differences in self-reported behaviours could be due to this bias.

In conclusion, it is clear from the data presented in this study that HIV prevention among IDUs remains a key challenge for Pakistan in its overall effort to control HIV. This issue is especially important considering the overlap between IDU populations and other high-risk sexual networks (via connections such as noninjecting sexual partners of IDUs) that is presented in other papers in this supplement. The rising HIV prevalence among IDUs increases the potential for HIV to spread into these other high-risk sexual networks and from there possibly into the general population. To effectively address HIV among IDUs and other populations, it is important that these surveillance data are used in the planning and delivery of prevention programmes, and that the connection between programmes, surveillance and monitoring activities, and the community be strengthened.

Acknowledgements We thank the surveillance team for their efforts in mapping, data collection, specimen collection and data entry. We thank Dr Tahira Reza for data management and helpful discussions. We also thank the participants who took part in the surveys for their time and participation.

Contributors CPA and SYS were primarily responsible for the development of this article. SS was responsible for data analysis and composed drafts and CA critically reviewed and revised drafts. FE, SO, TR, AA, NM, LHT and JFB were involved in the conception of the article and critically reviewed drafts.

Funding The Canada-Pakistan HIVIAIDS Surveillance Projected was funded by the Canadian International Development Agency.

\section{Competing interests None.}

Provenance and peer review Commissioned; externally peer reviewed.

Open Access This is an Open Access article distributed in accordance with the Creative Commons Attribution Non Commercial (CC BY-NC 3.0) license, which permits others to distribute, remix, adapt, build upon this work non-commercially, and license their derivative works on different terms, provided the original work is properly cited and the use is non-commercial. See: http://creativecommons.org/ licenses/by-nc/3.0/ 


\section{REFERENCES}

1 UNAIDS. AIDS Epidemic Update: December 2007 http://www.data.unaids.org/pub/ epislides/2007/2007_epiupdate_en.pdf (accessed 29 Apr 2008).

2 Choopanya K, Vanichseni S, Des Jarlais DC, et al. Risk factors and HIV seropositivity among injecting drug users in Bangkok. AIDS 1991;5:1509-13.

3 Des Jarlais DC, Friedman SR, Novick DM, et al. HIV-1 infection among intravenous drug users in Manhattan, New York City, from 1977 through 1987. JAMA 1989;261:1008-12.

4 Sarkar S, Das N, Panda S, et al. Rapid spread of HIV among injecting drug users in north-eastern states of India. Bull Narc 1993;45:91-105.

5 Kelly JA, Amirkhanian YA. The newest epidemic: a review of HIVIAIDS in Central and Eastern Europe. Int J STD AIDS 2003;14:361-71.

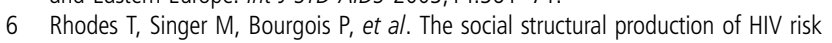
among injecting drug users. Soc Sci Med 2005;61:1026-44.

7 Rhodes T, Ball A, Stimson GV, et al. HIV infection associated with drug injecting in the newly independent states, eastern Europe: the social and economic context of epidemics. Addiction 1999;94:1323-6.

8 United Nations Office on Drug and Crime. Drug Use Survey. Vienna, 2002.

9 Achakzai M, Kassi M, Kasi PM. Seroprevalences and co-infections of HIV, hepatitis $C$ virus and hepatitis B virus in injecting drug users in Quetta, Pakistan. Trop Doct 2007;37:43-5.

10 United Nations Office on Drug and Crime. World Drug Report. Vienna, 2006.

11 Emmanuel F, Attarad A. Correlates of injection use of synthetic drugs among drug users in Pakistan: a case controlled study. J Pak Med Assoc 2006;56:119-24.

12 Strathdee SA, Zafar T, Brahmbhatt $\mathrm{H}$, et al. Rise in needle sharing among injection drug users in Pakistan during the Afghanistan war. Drug A/cohol Depend 2003;71:17-24.
13 National AIDS Control Program. HIV Second Generation Surveillance in Pakistan: National Report Round II 2006-07. Islamabad: Ministry of Health; 2007.

14 Parviz S, Fatmi Z, Altaf A, et al. Background of demographics and risk behaviors of injecting drug users in Karachi, Pakistan. Int J Infect Dis 2006;10:364-71

15 Kuo I, UI Hassan S, Galai N, et al. High HCV seroprevalence and HIV drug use risk behaviors among injection drug users in Pakistan. Harm Reduct J 2006;3:26. doi:10.1186/477-7517-3-26.

16 Rai MA, Warraich HJ, Ali SH, et al. HIVIAIDS in Pakistan: the battle begins. Retrovirology 2007;4:22.

17 Shaw SY, Emmanuel F, Adrien A, et al. The descriptive epidemiology of male sex workers in Pakistan: a biological and behavioural examination. Sex Transm Infect 2011;87:73-80

18 Blanchard JF, Khan A, Bokhari A. Variations in the population size, distribution and client volume among female sex workers in seven cities of Pakistan. Sex Transm Infect 2008;84(Suppl 2):ii24-7.

19 Emmanuel F, Blanchard J, Zaheer HA, et al. The HIVIAIDS Surveillance Project mapping approach: an innovative approach for mapping and size estimation for groups at a higher risk of HIV in Pakistan. AIDS 2010;24:S77-84.

20 Solomon SS, Desai M, Srikrishnan AK, et al. The profile of injection drug users in Chennai, India: identification of risk behaviours and implications for interventions. Subst Use Misuse 2010;45:354-67.

21 Pollini RA. Problematic use of prescription-type opioids prior to heroin use among young heroin injectors. Subst Abuse Rehabil 2011;2:173-80.

22 Morison L. The global epidemiology of HIV/AIDS. Br Med Bull 2001;58:7-18. 